\title{
Current trends in the treatment of infantile spasms
}

This article was published in the following Dove Press journal:

Neuropsychiatric Disease and Treatment

18 May 2009

Number of times this article has been viewed

\section{Chang-Yong Tsao}

Clinical Pediatrics and Neurology, The Ohio State University, College of Medicine, Columbus, Ohio, USA
Correspondence: Chang-Yong Tsao

700 Children's Dr Columbus,

Ohio 43205, USA

Tel + | 6|4-722-469|

Fax + I 614-722-4633

Email changyong.tsao@

nationwidechildrens.org
Abstract: Infantile spasms are an epilepsy syndrome with distinctive features, including age onset during infancy, characteristic epileptic spasms, and specific electroencephalographic patterns (interictal hypsarrhythmia and ictal voltage suppression). Adrenocorticotropic hormone (ACTH) was first employed to treat infantile spasms in 1958, and since then it has been tried in prospective and retrospective studies for infantile spasms. Oral corticosteroids were also used in a few studies for infantile spasms. Variable success in cessation of infantile spasms and normalization of electroencephalograms was demonstrated. However, frequent significant adverse effects are associated with ACTH and oral corticosteroids. Vigabatrin has been used since the 1990s, and shown to be successful in resolution of infantile spasms, especially for infantile spasms associated with tuberous sclerosis. It is associated with visual field constriction, which is often asymptomatic and requires perimetric visual field study to identify. When ACTH, oral corticosteroids, and vigabatrin fail to induce cessation of infantile spasms, other alternative treatments include valproic acid, nitrazepam, pyridoxine, topiramate, zonisamide, lamotrigine, levetiracetam, felbamate, ganaxolone, liposteroid, thyrotropin-releasing hormone, intravenous immunoglobulin and a ketogenic diet. Rarely, infantile spasms in association with biotinidase deficiency, phenylketonuria, and pyridoxine-dependent seizures are successfully treated with biotin, a low phenylalanine diet, and pyridoxine, respectively. For medically intractable infantile spasms, some properly selected patients may have complete cessation of infantile spasms with appropriate surgical treatments.

Keywords: infantile spasms, adrenocorticotropic hormone, oral corticosteroids, vigabatrin

\section{Introduction}

Infantile spasms are an age-specific epilepsy syndrome characterized by flexor, extensor, and mixed flexor-extensor spasms which often occur in clusters and onset during first 2 years of life. ${ }^{1}$ Most of the infantile spasms are symptomatic and $9 \%$ to $15 \%$ of the cases were cryptogenic. ${ }^{2}$ West syndrome is diagnosed when infantile spasms, hypsarrhythmia and mental retardation are present.

\section{Epidemiology}

The incidence of infantile spasms is estimated at 0.20 to 0.60 per $100 .^{3-8}$ The prevalence is 0.15 to $0.20 / 1000$ children age 10 or younger. ${ }^{8,9}$

\section{Clinical features and long-term outcome}

The peak onset of infantile spasms is between 3 and 7 months, 93\% before age 2 years; however, onset at birth and at 4.5 years has been reported. ${ }^{10}$ The spasms are bilateral 
sudden muscle contractions involving neck, trunk, and four extremities, and may be flexor, extensor, or mixed types. The spasms may be single, but often occur in clusters. The majority of the infantile spasms are symptomatic and may be associated with prenatal, perinatal, and postnatal causes, including brain dysgenesis; neurocutaneous syndromes such as tuberous sclerosis; metabolic disorders; chromosomal syndrome such as Down syndrome or gene abnormalities such as ARX gene mutations; hypoxic ischemic encephalopathy; brain tumor; neonatal bacterial meningitis; and herpes simplex encephalitis, among others. ${ }^{1,10-12}$ Cryptogenic cases, characterized by lack of obvious evidence of brain damage or known etiology, comprise $9 \%$ to $15 \%$ of infantile spasms. $^{2}$ The typical interictal electroencephalogram is hypsarrhythmia and classical ictal correlates may consist of fast wave bursts, high voltage slow waves, and generalized voltage attenuation or electrodecremental response. ${ }^{13,14}$ About $10 \%$ to $25 \%$ of the patients with infantile spasms recover spontaneously. ${ }^{11,15,16}$ In the pre-adrenocorticotropic hormone $(\mathrm{ACTH})$ era, long-term follow-up in 103 patients with infantile spasms, at age 5 years or older, showed that $11 \%$ of children still had infantile spasms, $45 \%$ had other seizure types, and $55 \%$ were seizure-free; $13 \%$ over 1 year of age had normal intellectual capacity, and mortality was $11 \%$ by age 2 years. ${ }^{17}$

In a prospective study of the outcome of 64 infants with infantile spasms treated during controlled studies of ACTH and prednisone, mean duration of follow-up was 50 months, and there was a 5\% mortality rate in symptomatic patients; 2 of 8 cryptogenic patients were cognitively normal, compared with 1 of the 56 symptomatic patients; infantile spasms persisted in $42 \%$ of children, whereas $53 \%$ of patients developed other seizure types and $47 \%$ were seizure-free; no difference in long-term intellectual outcome or epilepsy was associated with delay in treatment $>5$ weeks from onset of infantile spasms. ${ }^{18}$ However, in another prospective study of 102 infants with infantile spasms, with follow-up beyond 6 years, $50 \%$ of ACTH-treated patients were developmentally normal, 62\% were seizure-free, and $39 \%$ had a normal EEG; better neurodevelopmental outcome was seen with early therapy of $<1$ month. ${ }^{19}$ Two other studies also revealed favorable long-term outcome of ACTH treatment within 1 month of onset for cryptogenic infantile spasms. ${ }^{20,21}$ Some studies reported equal efficacy of infantile spasms treatment in both symptomatic and cryptogenic groups, ${ }^{22}$ but other studies found a better response of treatment in the cryptogenic group. ${ }^{23,24}$ Additionally, the effect of hormonal therapy on long-term neurodevelopmental outcome is unclear, with some studies reporting a positive association between initial responsiveness to ACTH and improved long-term intellectual development, ${ }^{19,23,25}$ but other studies found no significant difference in prognosis between initial responders and nonresponders to hormonal therapy. ${ }^{18,26}$ Of patients with infantile spasms, 20\% to $50 \%$

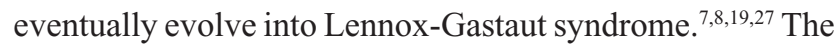
patients with cryptogenic infantile spasms have $30 \%$ to $50 \%$ mental retardation compared with $80 \%$ to $95 \%$ for patients with symptomatic etiology. $4,8,20,25-28$

\section{Treatment}

The treatment of infantile spasms remains very challenging throughout the world. Over the years, the treatment choices have been surveyed and evaluated in the United States, Japan, the United Kingdom, and Europe. ${ }^{29-34}$ For example, in 1994, the survey report in the Child Neurology Society revealed $\mathrm{ACTH}$ as the first choice for the treatment of the infantile spasms, followed by valproic acid and oral corticosteroids as second and third choices, respectively. ${ }^{30}$ In another example, in 2000, a survey of the treatment of infantile spasms by the Japanese Epilepsy Society showed that vitamin B6 was the preferred first-line drug, followed by the combination of vitamin B6 and valproate or monotherapy with valproate; corticotropin was the third choice. ${ }^{31}$ Other surveys will be discussed later in the paper.

\section{ACTH (adrenocorticotropic hormone) \\ Mechanism of ACTH and prednisone}

ACTH may reduce neuronal excitability in infantile spasms by two mechanisms of action: (1) inducing steroid release and (2) a direct, steroid-independent action on melanocortin receptors. These combined effects may explain the robust, established clinical effects of ACTH in the therapy of infantile spasms. ${ }^{35}$ Additionally, suppression of corticotropin-releasing hormone $(\mathrm{CRH})$, an excitant neuropeptide, by ACTH/steroids was proposed as another mechanism for ACTH treatment of infantile spasms. ${ }^{36}$ However, there is considerable debate about the reasons why ACTH and prednisone are useful in infantile spasms, their mechanism of action, and their long-term effects on brain development. ${ }^{37}$

The therapeutic effect of ACTH in infantile spasms was initially reported in a series of children with infantile spasms and hypsarrhythmia. ${ }^{38}$ Since then, both prospective and retrospective studies with ACTH have been conducted for the treatment of infantile spasms. 
In one prospective study, 26 patients receiving the high-dose therapy were treated as follows: $150 \mathrm{U} / \mathrm{m}^{2} /$ day for 3 weeks, $80 \mathrm{U} / \mathrm{m}^{2} /$ day for 2 weeks, $80 \mathrm{U} / \mathrm{m}^{2}$ every other day for 3 weeks, and $50 \mathrm{U} / \mathrm{m}^{2} /$ day every other day for 1 week, with the dosage then tapered to zero during a 3-week period; the 24 patients assigned to the low-dose therapy group received 20 to $30 \mathrm{U} /$ day for 2 to 6 weeks; the dosage was then tapered to zero during a 1-week period. ${ }^{39}$ The response was defined as cessation of infantile spasms and disappearance of hypsarrhythmia. Among 26 patients treated with the high-dose therapy, 13 (50\%) responded; of the 24 patients treated with the low-dose therapy, 14 (58\%) responded. No significant difference in the cessation of infantile spasms and improvement of the electroencephalogram was demonstrated in the two groups. Additionally, no difference in the relapse rate between the two groups was noted. Furthermore, the side effects seen in both treatment groups were similar, except that hypertension occurred more frequently in the high-dose group. In another report, there is no evidence that high-dose ACTH treatment $\left(150 \mathrm{U} / \mathrm{m}^{2} /\right.$ day $)$ is more effective than low-dose ACTH (20-30 U/day). ${ }^{23}$ The relapses of the infantile spasms often occur in one third to one half of patients, and a second course of ACTH is often effective. ${ }^{22} \mathrm{In}$ another prospective randomized controlled study, low-dose ACTH $(0.005 \mathrm{mg} / \mathrm{kg} /$ day $=0.2 \mathrm{IU} / \mathrm{kg} /$ day $)$ or high-dose $(0.025 \mathrm{mg} / \mathrm{kg} /$ day $=1 \mathrm{IU} / \mathrm{kg} /$ day $)$ synthetic ACTH therapy showed no difference in the initial and long-term seizure and developmental outcomes in the 17 responders who were followed up for longer than 1 year after the completion of $\mathrm{ACTH}$ therapy. ${ }^{40}$ The optimal dose of ACTH is still unknown based on the above studies.

In the report of the American Academy of Neurology and the Child Neurology Society on the medical treatment of infantile spasms, 14 studies on ACTH including 5 randomized controlled studies, 4 prospective, open-label trials, and 5 retrospective studies were reported. ${ }^{11} \mathrm{ACTH}$ dosage ranged from $0.2 \mathrm{IU} / \mathrm{kg}$ to $150 \mathrm{IU} / \mathrm{m}^{2}$, the duration of treatment was from 4 to 12 weeks, the rate of cessation of infantile spasms was from $42 \%$ to $87 \%$, time from initial treatment to cessation of infantile spasms was from 7 to 12 days, and the relapse rate of infantile spasms varied from $15 \%$ to $33 \% .^{11}$

\section{Oral corticosteroids}

Five studies including 2 randomized controlled studies, 2 prospective open-label studies and 1 retrospective study with 2 to $3 \mathrm{mg} / \mathrm{kg}$ prednisone or prednisolone from 2 to 32 weeks. ${ }^{11}$ The cessation rate of infantile spasms varied from $29 \%$ to $59 \%$.

\section{ACTH versus oral corticosteroids}

A prospective randomized single-blinded study with 2-week ACTH $150 \mathrm{IU} / \mathrm{m}^{2}$ was compared with 2-week oral prednisone $2 \mathrm{mg} / \mathrm{kg}$, revealing superior efficacy of high-dose ACTH in the cessation of infantile spasms and disappearance of hypsarrhythmia. ${ }^{41}$ Of 15 infants randomized to ACTH, 13 responded by EEG and clinical criteria (86.6\%); 4 of the 14 patients given prednisone responded (28.6\%). A doubleblind, placebo-controlled, crossover study to compare the therapeutic effectiveness of ACTH (20 to 30 units/day) with that of prednisone $(2 \mathrm{mg} / \mathrm{kg} /$ day $)$ showed no difference in the cessation of infantile spasms and disappearance of hypsarrhythmia between ACTH and prednisone. ${ }^{22}$ High-dose ACTH $150 \mathrm{IU} / \mathrm{m}^{2}$ was superior to prednisone $3 \mathrm{mg} / \mathrm{kg}$ in the cessation of infantile spasms with $100 \%$ in ACTH versus $59 \%$ in prednisone, $97 \%$ disappearance of hypsarrhythmia in ACTH versus $50 \%$ in prednisone. ${ }^{24}$ However, some patients who do not initially respond to ACTH may respond to prednisone and vice versa. ${ }^{22}$

\section{Side effects of ACTH and oral corticosteroids}

Hypertension $0 \%$ to $37 \%$ (4 studies), irritability $37 \%$ to $100 \%$ (3 studies), infection 14\% (1 study), cerebral atrophy $62 \%$ ( 1 study), 5 deaths in 304 cases ( 2 were associated with sepsis attributed to ACTH) were seen in randomized controlled studies. ${ }^{11}$

\section{Vigabatrin}

Vigabatrin, a structural analogue of gamma-aminobutyric acid (GABA), is an irreversible inhibitor of GABA transaminase and increases the GABA levels, an inhibitory neurotransmitter, in the brain..$^{42}$ In a randomized, placebocontrolled study of vigabatrin as first-line treatment of infantile spasms, compared with baseline, the patients treated with vigabatrin had a $78 \%$ reduction in infantile spasms compared with $26 \%$ in the group treated with placebo, at the end of the double-blind phase. ${ }^{29}$ In a randomized trial of vigabatrin in patients with infantile spasms, resolution rate of infantile spasms was $23 \%$ at 2 weeks after treatment, and $65 \%$ at the end of a 3-month open-label period; the efficacy and safety of vigabatrin in patients with infantile spasms, particularly among those with infantile spasms secondary to tuberous sclerosis, was demonstrated. ${ }^{43}$ In other open-label uncontrolled prospective studies, the response rate was better in cryptogenic infantile spasms (50\% to $100 \%)$ compared with the symptomatic cases ( $0 \%$ to $59 \%)$, the time from initiation of therapy to cessation of infantile spasms varied 
from 12 to 35 days, and the vigabatrin dosages ranged from 18 to $200 \mathrm{mg} / \mathrm{kg} / \mathrm{day} .{ }^{11}$ Additionally, the treatment response of infantile spasms to vigabatrin in the infants with tuberous sclerosis was uniformly favorable, with cessation of infantile spasms varying from $91 \%$ to $100 \%{ }^{43-49}$

Vigabatrin 100 to $150 \mathrm{mg} / \mathrm{kg} /$ day was compared with $\mathrm{ACTH}$ in the treatment of infantile spasms and the resolution rate of infantile spasms was similar for both vigabatrin and ACTH; however, the improvement of hypsarrhythmia was better for ACTH. ${ }^{48,50}$ In the United Kingdom, ACTH treatment induced complete cessation of infantile spasms better than vigabatrin initially, but not at 12 to 14 months of age; better initial cessation of infantile spasms by ACTH treatment in those with no identified underlying etiology may lead to improved developmental outcome. ${ }^{51}$

\section{Side effects of vigabatrin}

In both randomized controlled studies and open-label uncontrolled studies, sedation, irritability, insomnia and hypotonia were reported in vigabatrin treatment. ${ }^{11}$ Concentric visual field defects and abnormalities in electroretinograms were also demonstrated in children; however, the incidence in infants under 1 year of age is unknown currently. ${ }^{11,52-54}$

\section{Valproic acid}

Valproic acid enhances GABA-ergic inhibitory system at the cortical and subcortical levels and blocks neuronal firing by blocking voltage-gated sodium channels. ${ }^{42}$ In an uncontrolled, open-label, prospective study, cessation of infantile spasms in $73 \%$ and resolution of hypsarrhythmia in $91 \%$ of 22 patients (18 with symptomatic infantile spasms and 4 with cryptogenic infantile spasms) were reported after 6 months of therapy with valproic acid 40 and $100 \mathrm{mg} / \mathrm{kg} /$ day. ${ }^{55}$ However, relapse of infantile spasms in $23 \%$ of patients was seen in the first 7 months of treatment. In another open-label, uncontrolled, prospective study, cessation of infantile spasms was seen in $72 \%$ of the patients with infantile spasms after 3 months of treatment with valproic acid. ${ }^{56}$

Common side effects of valproic acid include weight gain, nausea, vomiting, hair loss, easy bruising, tremor; rare idiosyncratic effects consist of agranulocytosis, Stevens-Johnson syndrome, aplastic anemia, hepatic failure, dermatitis-rash, serum sickness, and pancreatitis. ${ }^{42,57}$

\section{Nitrazepam}

Mechanism of nitrazepam in the treatment of infantile spasms may be related to their effect in modification of the sensitivity of GABA receptors. ${ }^{58}$ In the retrospective case series, nitrazepam 0.5 to $3.5 \mathrm{mg} / \mathrm{kg} /$ day was reported to induce resolution of infantile spasms from $30 \%$ to $54 \%$ and disappearance of hypsarrhythmia from $15 \%$ to $46 \% .{ }^{59,60}$ Another prospective randomized multicenter study comparing corticotropin with nitrazepam revealed no difference in efficacy in the treatment of infantile spasms. ${ }^{61}$

Nitrazepam was associated with excess sedation, hypersalivation, swallowing difficulty, high incidence of aspiration pneumonia, and several deaths. ${ }^{62,63}$

\section{Pyridoxine}

Pyridoxine is a coenzyme of glutamic acid decarboxylase and enhances GABA synthesis. ${ }^{64}$ Low levels of GABA in cerebrospinal fluid of infants with infantile spasms were reported. ${ }^{65}$ Pyridoxine is the first treatment of choice for infantile spasms in Japan. ${ }^{31,32,66}$ Two uncontrolled prospective open-label studies in infantile spasms revealed efficacy for infantile spasms. ${ }^{67,68}$ At dosages of pyridoxine $>1 \mathrm{~g} /$ day (usual dose of pyridoxine 10 to $50 \mathrm{mg} / \mathrm{kg} /$ day), a complete control of infantile spasms was reported in $35 \%$ to $40 \%$ of cryptogenic cases but only $10 \%$ of symptomatic cases. ${ }^{67}$ Side effects of high-dose pyridoxine include loss of appetite, irritability and vomiting. ${ }^{68}$

Pyridoxine-dependent seizures are characterized by intractable seizures including infantile spasms that are not controlled with anticonvulsants but that respond both clinically and electrographically to $100 \mathrm{tp} 500 \mathrm{mg}$ of intravenous pyridoxine. ${ }^{69}$ Pyridoxine-dependent seizures, an autosomal recessive disorder, is caused by mutations in the ALDH7A1 gene on chromosome $5 \mathrm{q} 31 .{ }^{69}$ The patients require lifetime treatment with pyridoxine at 15 to $20 \mathrm{mg} / \mathrm{kg} /$ day. ${ }^{69}$

\section{Zonisamide}

Zonisamide blocks repetitive firing of voltage-sensitive sodium channels, reduces voltage-sensitive T-type calcium currents without affecting L-type calcium currents, and is a weak carbonic anhydrase inhibitor. ${ }^{70}$ In one add-on nonblind study, zonisamide 4 to $20 \mathrm{mg} / \mathrm{kg} /$ day in 27 children with infantile spasms (25 symptomatic and 3 cryptogenic cases) induced cessation of infantile spasms and resolution of hypsarrhythmia in 33\%; however, a 50\% recurrence rate was also reported. ${ }^{71}$ In another add-on nonblind study, 16 patients with infantile spasms (13 symptomatic and 3 cryptogenic cases) were treated with 4 to $8 \mathrm{mg} / \mathrm{kg} /$ day zonisamide after failing to respond to pyridoxine and valproic acid. Only 2 patients showed cessation of infantile spasms but no recurrence of infantile spasms after 26 months of follow-up. ${ }^{72}$ Zonisamide monotherapy 3 to $10 \mathrm{mg} / \mathrm{kg} /$ day was administered 
in 11 patients with newly diagnosed infantile spasms (cryptogenic 3, symptomatic 8) as the second-choice drug that failed to respond to high-dose vitamin B6. The cessation of infantile spasms and disappearance of the hypsarrhythmia in 4 symptomatic patients $(36 \%)$ were achieved after 1 to 5 days of treatment, however there were two relapses $(50 \%)$ 4 to 6 weeks after cessation of seizures. ${ }^{73}$ In another study, the long-term effectiveness of zonisamide was evaluated in 11 patients with West syndrome (7 symptomatic) who had cessation of spasms with zonisamide monotherapy. During the follow-up period (24 to 79 months), this response was maintained in 7 patients (relapse rate $=36 \%$ ). ${ }^{74}$ Recently, 6 of $23(26 \%)$ patients with symptomatic infantile spasms became spasm-free on zonisamide. ${ }^{75}$

Common side effects of zonisamide in children include anorexia, dizziness, ataxia, fatigue, somnolence, and confusion; rare idiosyncratic effects consist of nephrolithiasis, oligohydrosis, and hyperthermia. ${ }^{57}$

\section{Topiramate}

Topiramate blocks voltage-sensitive sodium channels, enhances the activity of GABA, an inhibitory neurotransmitter, blocks the action of glutamate, an excitatory neurotransmitter, and is also a weak carbonic anhydrase inhibitor. ${ }^{42,76}$ In a nonblind add-on pilot study with topiramate $25 \mathrm{mg}$ daily up to $24 \mathrm{mg} / \mathrm{kg} /$ day on 11 children with refractory infantile spasms, 5 (45\%) became spasm-free during the study, with absence of infantile spasms and hypsarrhythmia. ${ }^{77}$ Eleven children with infantile spasms who completed the pilot study entered an 18-month study in which the dosages of topiramate and other anticonvulsants were adjusted to optimal response (maximum, $50 \mathrm{mg} / \mathrm{kg} / \mathrm{day}$ ). Four (50\%) children were spasmfree, $7(88 \%)$ had experienced a $\geq 50 \%$ reduction in spasms, and $3(38 \%)$ were able to achieve topiramate monotherapy. ${ }^{78}$ Topiramate was well tolerated in that no patients discontinued because of adverse events. In a prospective, 2-month study with topiramate 3 to $27 \mathrm{mg} / \mathrm{kg} /$ day in 15 children with recently diagnosed infantile spasms, 3 patients became spasm-free (20\%), 5 had $>50 \%$ reduction, 3 had at least $25 \%$ reduction, 4 patients did not respond, and 3 of 15 patients had cessation of hypsarrhythmia. ${ }^{79}$ Topiramate treatment in children with West syndrome was reported in a retrospective multicenter evaluation of 100 patients: $17.5 \%$ of patients became free of seizures, and in $47 \%$, the seizure frequency decreased by at least 50\%; additionally, hypsarrhythmia remitted in 18 of 83 cases. $^{80}$

Common side effects of topiramate include anorexia, weight loss, word-finding disturbance, cognitive slowing, ataxia, poor concentration, dizziness, fatigue, paresthesia, somnolence; rare side effects consist of nephrolithiasis, hypohidrosis, acute angle closure glaucoma. ${ }^{42,57}$

\section{Felbamate}

Felbamate potentiates GABA-mediated inhibition, blocks voltage-dependent sodium channels, and the ionic channel at the N-methyl-d-aspartate receptor. ${ }^{42}$ In one nonblind add-on study, felbamate 15 to $45 \mathrm{mg} / \mathrm{kg} /$ day resulted in cessation of infantile spasms in 3 of 4 patients, all refractory to conventional antiepileptic drugs ${ }^{81}$ In another nonblind study for refractory infantile spasms, in which 4 of 6 patients were refractory to both corticosteroids and new antiepileptic drugs (vigabatrin and lamotrigine), felbamate 15 to $45 \mathrm{mg} / \mathrm{kg} /$ day treatment decreased seizure frequency by $75 \% .{ }^{82}$

Felbamate common side effects consist of nausea, vomiting, anorexia, weight loss, insomnia, dizziness, headache and ataxia; rare serious idiosyncratic effects include aplastic anemia, and hepatic failure. ${ }^{42,57}$

\section{Lamotrigine}

Lamotrigine has been shown to act at voltage-sensitive sodium channels, stabilizing neural membranes and inhibiting the release of excitatory neural transmitters. ${ }^{42}$ The dosage of lamotrigine can be titrated slowly up to $5 \mathrm{mg} / \mathrm{kg} /$ day when combined with valproate, but can be gradually increased to $15 \mathrm{mg} / \mathrm{kg} /$ day when not combined with valproate. In a single-blind, placebo-controlled, add-on study, 30 patients with infantile spasms refractory to conventional antiepileptic drugs and to vigabatrin and corticotropin were treated with lamotrigine, 9 patients showing $>50 \%$ decrease in infantile spasms, 5 of these with complete cessation of spasms. ${ }^{83}$ Three infants affected with symptomatic West syndrome, unresponsive to vigabatrin and to ACTH, were successfully treated with very small doses of lamotrigine. ${ }^{84}$ Common side effects of lamotrigine include rash, nausea, dizziness, and somnolence; rare idiosyncratic effects include StevensJohnson syndrome and hypersensitivity syndrome. ${ }^{42,57}$

\section{Levetiracetam}

Levetiracetam binds to synaptic vesicle protein, has actions on neuronal GABA- and glycine-gated currents, as well as voltage-dependent potassium currents, however, its exact mechanism of action is unknown. ${ }^{57}$ In an open-label addon study of levetiracetam 10 to $60 \mathrm{mg} / \mathrm{kg} /$ day in refractory childhood epilepsy syndromes, efficacy was demonstrated in one patient's infantile spasms. ${ }^{85}$ Refractory infantile spasms in another infant were responsive to levetiracetam 
$15 \mathrm{mg} / \mathrm{kg} / \mathrm{day}$, resulting in cessation of infantile spasms for 6 months. ${ }^{86}$ Treatment with levetiracetam $30 \mathrm{mg} / \mathrm{kg} /$ day for cryptogenic West syndrome resulted in cessation of infantile spasms in 2 patients, a $50 \%$ reduction in seizure frequency in 2 patients, but no improvement in seizure frequency in another patient. There were no relapses in the two patients at 6 months after the cessation of seizures. ${ }^{87}$

Common side effects of levetiracetam include somnolence, headache, anorexia, and nervousness. Less frequent side effects consist of agitation, aggression, anxiety, or depression. ${ }^{57}$

\section{Thyrotropin-releasing hormone}

A daily dose of thyrotropin-releasing hormone 0.5 to $1 \mathrm{mg}$ was administered intravenously or intramuscularly for 1 to 4 weeks. The follow-up periods were 3 to 12 months (mean 6 months). Complete cessation of spasms was achieved in 7 of $13(53.7 \%)$ of those with infantile spasms, and marked improvement of electroencephalograms was observed in 8 of $13(61.5 \%)$ of these. ${ }^{88}$ Thyrotropin-releasing hormone was shown to increase cerebrospinal fluid kynurenine level. ${ }^{89}$ Thyrotropin-releasing hormone may act as an antiepileptic through a kynurenine mechanism, considering that kynurenic acid acts as an antagonist on the N-methylD-aspartate receptor complex. ${ }^{90}$ Additionally, thyrotropinreleasing hormone-mediated increase in GABA release has also been demonstrated and may contribute to its anti-epileptic effects. ${ }^{91}$ The effectiveness of thyrotropinreleasing hormone was also reported in West syndrome, Lennox-Gastaut syndrome, and early infantile epileptic encephalopathy that were intractable to anticonvulsants and adrenocorticotrophic hormone..$^{90,92}$

\section{Ganaxolone}

Ganaxolone is an allosteric modulator of GABA receptors acting through binding sites, which are distinct from the benzodiazepine binding site. ${ }^{93,94}$ In a multicenter, openlabel, add-on trial, investigating the safety and efficacy of ganaxolone up to $36 \mathrm{mg} / \mathrm{kg} /$ day in children with refractory infantile spasms, infantile spasm frequency was reduced by at least $50 \%$ in $33 \%$ of these subjects, with an additional $33 \%$ experiencing some improvement (25\% to $50 \%$ reduction in spasm frequency); ganaxolone was well tolerated, and adverse events attributed to ganaxolone were generally mild, consisting of somnolence, diarrhea, nervousness, and vomiting. ${ }^{95}$ In another add-on nonblind study, ganaxolone treatment in 20 children with infantile spasms refractory to corticosteroids, lamotrigine and vigabatrin, only 1 patient had cessation of infantile spasms and $>50 \%$ decrease in seizure frequency in $50 \%$ of the patients. ${ }^{58}$

\section{Liposteroid}

Dexamethasone palmitate (liposteroid) was used for the treatment of West syndrome and compared with adrenocorticotropic hormone (ACTH) therapy. ${ }^{96}$ A single intravenous injection of liposteroid $(0.25 \mathrm{mg} / \mathrm{kg})$ was administered seven times in 3 months (total dosage $=1.75 \mathrm{mg} / \mathrm{kg}$ ) to 5 symptomatic patients with West syndrome, aged 4 to 11 months. ACTH $(0.025 \mathrm{mg} / \mathrm{kg} /$ day $)$ was administered intramuscularly for 6 weeks (total dosage $=0.625 \mathrm{mg} / \mathrm{kg}$ ) to 5 symptomatic patients with West syndrome, aged 6 to 10 months. Infantile spasms and hypsarrhythmia on EEG disappeared in all 5 patients in the liposteroid therapy group within 4 doses; in the ACTH therapy group, infantile spasms and hypsarrhythmia on EEG similarly disappeared during treatment in all 5 patients, but infantile spasms reappeared 2 months after therapy in 2 patients. No notable adverse reactions occurred in the liposteroid group, but transient dysfunction of the thyroid and anterior pituitary gland and increased levels of serum cortisol were experienced in the ACTH group. ${ }^{96}$ In another study, a single intravenous injection of liposteroid $(0.25 \mathrm{mg} / \mathrm{kg})$ was administered 12 times in 1 month (total dosage $3.0 \mathrm{mg} / \mathrm{kg}$ ) to 4 patients with West syndrome. All 4 patients previously had daily seizures uncontrolled by conventional antiepileptic drugs, such as valproic acid, clonazapam or zonisamide. Infantile spasms and hypsarrhythmia on EEG disappeared in 1 patient within 4 doses; a greater than 50\% decrease in seizures, and EEG improvement, were found in another 2 patients; no notable effects were seen in the other 2 patients. There were no clinically significant adverse reactions throughout the therapy. ${ }^{97}$

\section{Sulthiame}

Sulthiame is a carbonic anhydrase inhibitor that is widely used to treat partial and myoclonic seizures. Sulthiame ( 5 to $10 \mathrm{mg} / \mathrm{kg} /$ day) was studied in a randomized doubleblind placebo-controlled add-on trial on baseline pyridoxine medication for the primary therapy of West syndrome and was found to have a positive effect in the primary therapy of West syndrome. Based on the intention to treat, $6(30 \%)$ of 20 patients responded to sulthiame, reaching complete cessation of infantile spasms and resolution of hypsarrhythmia, while no patients on placebo responded $(p<0.025) .{ }^{98}$ Side effects of sulthiame occurred in $48 \%$ of patients, including vomiting in $38 \%$, somnolence in $20 \%$, restlessness in $16 \%$, loss of appetite in $5.5 \%$, and diarrhea in $3 \% .{ }^{98}$ 


\section{Intravenous immunoglobulin (IVIg)}

In one study, 6 children with cryptogenic infantile spasms and 5 with symptomatic infantile spasms were treated with IVIg at 100 to $200 \mathrm{mg} / \mathrm{kg}$ of body weight at intervals of 2 or 3 weeks (6 to 10 administrations). All 6 patients with cryptogenic West syndrome showed complete remission in accordance with normalized electroencephalogram. Of the 5 patients with symptomatic West syndrome, 1 showed cessation of clinical spasms in agreement with EEG improvement and 2 others revealed transient cessation of spasms with recurrence. ${ }^{99}$ Five of 23 patients with infantile spasms experienced cessation of infantile spasms with $1 \mathrm{~g} / \mathrm{kg}$ of IVIg for 2 days, repeated every 3 weeks for 6 months. ${ }^{100}$

\section{Ketogenic diet}

Since the early 1920s, the ketogenic diet has been used successfully to treat patients with intractable epilepsy; however, the mechanism by which the diet protects against seizures is unknown. The ketogenic diet is a calorie-restricted diet in which the fat:carbohydrate plus protein ratio ranges from 2:1 to 5:1. During a 4-year period, 23 children with infantile spasms, aged 5 months to 2 years, were started on the ketogenic diet; at 3, 6, 9, and 12 months, $38 \%, 39 \%, 53 \%$, and $46 \%$, respectively, of all patients currently on the diet were $>90 \%$ improved ( 3 were seizure-free at 12 months); $67 \%, 72 \%, 93 \%$, and $100 \%$ were $>50 \%$ improved. ${ }^{101}$ In another retrospective study, the ketogenic diet achieved the spasm-free state in $53.5 \%(23 / 43)$ of patients and a greater than $90 \%$ reduction of spasms in $62.8 \%$ (27/43) of patients; the spasm outcomes were highly concordant with improvements in EEG findings and development. ${ }^{102}$ In a retrospective study, a case-control evaluation was performed for the ketogenic diet versus ACTH for new-onset infantile spasms, including 13 patients on the ketogenic diet and 20 patients on high-dose ACTH. Eight of 13 (62\%) infants treated with the ketogenic diet were spasm-free within 1 month, compared with 18 of $20(90 \%)$ treated initially with ACTH; ACTH-treated infants were more likely to have a normal EEG at 1 month; side effects ( $31 \%$ vs $80 \%, p=0.006)$ and relapse rate after initial success $(12.5 \%$ vs $33 \%, \mathrm{p}=0.23)$ were lower with the ketogenic diet. ${ }^{103}$

Early side effects in the initial 4 weeks of treatment may consist of transient dehydration, nausea, vomiting, diarrhea, constipation, lethargy, hypoglycemia, hypercholesterolemia, hypertriglyceridemia, hyperuricemia, hypoproteinemia, hypomagnesemia, hyponatremia, low concentrations of high-density lipoprotein, hepatitis, acute pancreatitis, metabolic acidosis, hemolytic anemia, and Fanconi renal tubular acidosis; later side effects include osteopenia, renal stones, cardiomyopathy, secondary hypocarnitinemia, and iron-deficiency anemia. ${ }^{104-106}$

\section{Combination therapies}

Nine infants with an underlying static encephalopathy and newly diagnosed infantile spasms were treated in an open study with ACTH and vigabatrin. The ACTH was discontinued after 4 to 6 weeks and the infants were maintained on vigabatrin alone. Following an initial response with complete cessation of infantile spasms in all 9 patients, a long-term spasm cessation for a mean of 19.2 months was reported in all but one child. ${ }^{107}$ Ninety-four patients with West syndrome were treated with sodium valproate and steroids, starting with hydrocortisone orally for 2 weeks. If spasms stopped, hydrocortisone was withdrawn, if spasms persisted, tetracosactrin (synthetic ACTH) was administered for another 2 weeks, and then hydrocortisone was slowly withdrawn. Spasms cessation was $72 \%$ for cryptogenic and $60 \%$ for symptomatic infantile spasms at 31-month follow-up. ${ }^{108}$ In 4 patients with cryptogenic and 1 patient with symptomatic (tuberous sclerosis) West syndrome, the combined therapy with topiramate and vigabatrin achieved a rapid and complete cessation of infantile spasms, and in 3 patients with cryptogenic West syndrome, the EEG also became normal. ${ }^{109}$

\section{Rare treatable symptomatic infantile spasms}

Rarely, infantile spasms occur in association with biotinidase deficiency, which can be treated with biotin successfully. ${ }^{110}$ Children with infantile spasms associated with phenylketonuria have been reported and were treated successfully with low phenylalanine diet and valproic acid or nitrazepam. ${ }^{111}$

\section{Surgical treatment}

In 4 infants with cryptogenic infantile spasms, positron emission tomography effectively identified unsuspected focal cortical dysplasia and all 4 patients were spasm-free after resective surgery. ${ }^{112}$ In another study, 23 infants and children underwent cortical resection ( $\mathrm{n}=15)$ or hemispherectomy $(\mathrm{n}=8)$ for intractable infantile spasms; convergence between electroencephalogram and neuroimaging localization was a prerequisite to surgery; at follow-up (range 4 to 67 months; mean 28.3 months), 15 children were spasm-free, 3 had $90 \%$ spasm reduction, 1 had $75 \%$ spasm reduction, and 4 failed 
to benefit from surgery in terms of seizure frequency. ${ }^{113}$ Twenty-four children receiving resection surgery for medically intractable infantile spasms showed a significant increase in developmental level at 2 years post surgery compared with presurgical levels. ${ }^{114} \mathrm{~A}$ favorable outcome of multiple sub-pial transection in 2 patients who had intractable atypical infantile spasms preceded by partial seizures, without any lateralized magnetic resonance imaging abnormalities, was recently reported. ${ }^{115}$ Infantile spasms associated with cortical dysplasia requiring treatment with lesionectomy in the right perirolandic area at 49 weeks conceptional age in one infant and left temporo-occipital disconnection at 45 weeks in the other infant, resulted in Engel classification I and catch-up developmental progress. ${ }^{116}$ For patients without a surgically resectable lesion, corpus callosotomy has been reported to improve dramatically infantile spasms, as well as other seizure types, such as drop attacks. ${ }^{117}$ After complete callosotomy, infantile spasms disappeared in $80 \%$ of 17 cases; drop attacks were dramatically reduced or completely stopped in $90 \%$ of the children. However, the excellent response of callosotomy in infantile spasms would require more studies for confirmation.

\section{Conclusion}

According to a 2008 Cochrane review, ${ }^{122}$ hormonal treatment resolves infantile spasms in more infants than vigabatrin, but this may or may not translate into a better long-term outcome. If prednisone or vigabatrin are used, then high dosage is recommended. Vigabatrin may be the treatment of choice for infantile spasms associated with tuberous sclerosis. In the United States of America, ACTH is probably an effective agent in the short-term treatment of infantile spasms and vigabatrin is possibly effective as suggested by the practice parameter: medical treatment of infantile spasms: report of the American Academy of Neurology and the Child Neurology Society. ${ }^{11}$ In Japan, the most recent survey in 2006 on treatment of infantile spasms reveals vitamin B6 as the first-choice drug, followed by valproic acid, zonisamide, and adrenocorticotropic hormone; however, in cryptogenic patients, ACTH was used most frequently, usually within 1 month after disease onset, followed by valproic acid, vitamin B6, and zonisamide. ${ }^{32}$ The 2004 National Institute for Clinical Excellence (NICE) Guidelines, ${ }^{118}$ the 2005 Scottish Intercollegiate Guidelines Network (SIGN) Guidelines, ${ }^{119}$ and the 2005 US Pediatric Epilepsy survey ${ }^{33}$ all support the use of vigabatrin as first-line therapy for infantile spasms associated with tuberous sclerosis complex. However, only the NICE Guidelines support vigabatrin as the drug of choice in symptomatic infantile spasms. In a recent survey in the United Kingdom, hormone treatment controlled infantile spasms better than vigabatrin initially, but not at 12 to 14 months of age. Better initial control of infantile spasms by hormone treatment in those with no identified underlying etiology may lead to improved developmental outcome..$^{51}$ In another recent survey, vigabatrin is the first choice for infantile spasms associated with tuberous sclerosis or symptomatic etiologies; ACTH and prednisone also are as good as other first-line options. ${ }^{34}$

When children fail to have complete cessation of infantile spasms after treatment with $\mathrm{ACTH}$, vigabatrin, or prednisone, some other medications have been used to treat infantile spasms with variable success in cessation of infantile spasms. In uncontrolled studies, these include topiramate, zonisamide, valproic acid, nitrazepam, lamotrigine, levetiracetam, felbamate, high-dose pyridoxine, liposteroid, ganaxolone, and thyrotropin-releasing hormone. Other alternative treatment for infantile spasms may consist of intravenous immunoglobulin and a ketogenic diet. Some selective children with medically intractable infantile spasms may have excellent success in resolution of spasms with proper surgical treatment options.

More research is necessary on the pathophysiology of infantile spasms, such as that conducted for recent animal models of infantile spasms, ${ }^{120}$ so that we can treat infantile spasms more successfully. Finally, infants with West syndrome could be identified several weeks before the occurrence of hypsarrhythmia by a typical EEG pattern, which may open the way for early intervention to prevent development of hypsarrhythmia and infantile spasms. ${ }^{121}$

\section{Disclosures}

The author discloses no conflicts of interest.

\section{References}

1. Lux AL, Osborne JP. A proposal for case definitions and outcome measures in studies of infantile spasms and West syndrome: consensus statement of the West Delphi group. Epilepsia. 2004;45:1416-1428.

2. Rima Nabbout and Olivier Dulac. Epileptic syndromes in infancy and childhood. Curr Opin Neurol. 2008;21:161-166.

3. Cowan LD, Hudson LS. The epidemiology and natural history of infantile spasms. J Child Neurol. 1991;6:355-364.

4. Sidenvall R, Eeg-Olofsson O. Epidemiology of infantile spasms in Sweden. Epilepsia. 1995;36:572-574.

5. Riikonen R, Donner M. Incidence and aetiology of infantile spasms from 1960-1976: a population study in Findland. Dev Med Child Neurol. 1979;21:333-343.

6. Ludvigsson P, Olafsson E, Siguroardottir S, Hauser WA. Epidemiologic features of infantile spasms in Iceland. Epilepsia. 1994;35:802-805. 
7. Rantala H, Putkonen T. Occurrence, outcome, and prognostic factors of infantile spasms and Lennox-Gastaut syndrome. Epilepsia. 1999;40:286-289.

8. Trevathan E, Murphy CC, Yeargin-Allsopp M. The descriptive epidemiology of infantile spasms among Atlanta children. Epilepsia 1999;40:748-751.

9. Cowan LD, Bodensteiner JB. Prevalence of the epilepsies in children and adolescents. Epilepsia. 1989;30:94-106.

10. Lacy Jr, Penry JK. Infantile spasms. New York, NY: Raven Press;1976.

11. Mackay MT, Weiss SK, Adams-Webber T, et al. Practice parameter: medical treatment of infantile spasms: report of the American Academy of Neurology and the Child Neurology Society. Neurology. 2004;62:1668-1681.

12. Poirier K, Eisermann M, Caubel I, Kaminska A, et al. Combination of infantile spasms, non-epileptic seizures and complex movement disorder: a new case of ARX-related epilepsy. Epilepsy Res. 2008;80:224-228.

13. Watanabe K, Negoro T, Okumura A. Symptomatology of infantile spasms. Brain Dev. 2001;23:453-466.

14. Kellaway P, Hrachovy RA, Frost JD, Zion T. Precise characterization and quantification of infantile spasms. Ann Neurol. 1979;6:214-218.

15. Hattori H. Spontaneous remission of spasms in West syndromeimplications of viral infection. Brain Dev. 2001;23:705-707.

16. Hrachovy RA, Glaze DG, Frost JD Jr. A retrospective study of spontaneous remission and long-term outcome in patients with infantile spasms. Epilepsia. 1991;32:212-214.

17. Gibbs EL, Anderson EM, Gibbs FA. Diagnosis and prognosis of hypsarrhythmia and infantile spasms. Pediatrics. 1954;13:66-73.

18. Glaze DG, Hrachovy RA, Frost JD Jr, Kellaway PR, Zion TE. Prospective study of outcome of infants with infantile spasms treated during controlled studies of ACTH and prednisone. J Pediatr. 1988;112:389-396.

19. Lombroso CT. A prospective study of infantile spasms: clinical andtherapeutic correlations. Epilepsia. 1983;24:135-158.

20. Riikonen R. Topical review: infantile spasms: therapy and outcome. J Child Neurol. 2004;19:401-404.

21. Kivity S, Lerman P, Ariel R, et al. Long-term cognitive outcomes of a cohort of children with cryptogenic infantile spasms treated with high-dose adrenocorticotropic hormone. Epilepsia. 2004;45: 255-262.

22. Hrachovy RA, Frost JD Jr, Kellaway P, Zion TE. Double-blind study of ACTH vs prednisone therapy in infantile spasms. $J$ Pediatr. 1983;103:641-645.

23. Riikonen R. A long-term follow-up study of 214 children with the syndrome of infantile spasms. Neuropediatrics. 1982;13:14-23.

24. Snead OC III, Benton JW, Myers GJ. ACTH and prednisone in childhood seizure disorders. Neurology. 1983;33:966-970.

25. Riikonen R. Long-term outcome of West syndrome: A study of adults with a history of infantile spasms. Epilepsia 1996;37:367-372.

26. Matsumoto A, Watanabe K, Negoro T, et al. Long-term prognosis after infantile spasms: A statistical study of prognositic factors in 200 cases. Dev Med Child Neurol. 1981;23:51-65.

27. Wong M, Trevathan E. Infantile spasms. Pediatr Neurol. 2001;24: 89-98.

28. Jeavons PM, Bower BD, Dimatrkoudi M. Long-term prognosis of 150 cases of "West syndrome." Epilepsia. 1973;14:153-164.

29. Appleton RE, Peters ACB, Mumford JP, Shaw DE. Randomised, placebo controlled study of vigabatrin as first-line treatment of infantile spasms. Epilepsia. 1999;40:1627-1633.

30. Bobele GB, Bodensteiner JB. The treatment of infantile spasms by childneurologists. J Child Neurol. 1994;9:432-435.

31. Ito M, Seki T, Takuma Y. Current therapy for West syndrome in Japan. J Child Neurol. 2000;15:424-428.

32. Tsuji T, Okumura A, Ozawa H, et al. Current treatment of West syndrome. J Child Neurol. 2007;22:560-564.

33. Wheless JW, Clarke DF, Carpenter D. Treatment of pediatric epilepsy: expert opinion, 2005. J Child Neurol. 2005;20:S1-S56.
34. Wheless JW, Clarke DF, Arzimanoglou A, Carpenter D. Treatment of pediatric epilepsy: European expert opinion. Epileptic Disord. 2007;9:353-412.

35. Brunson KL, Avishai-Eliner S, Baram TZ. ACTH treatment of infantile spasms: mechanisms of its effects in modulation of neuronal excitability. Int Rev Neurobiol. 2002;49:185-197.

36. Baram TZ. Pathophysiology of massive infantile spasms: perspective on the putative role of the brain adrenal axis. Ann Neurol. 1993;33: 231-236.

37. Holmes GL. Effect of non-sex hormones on neuronal excitability, seizures, and the electroencephalogram. Epilepsia. 1991; 2(Suppl 6): S11-S18.

38. Sorel L, Dusaucy-Bauloye A. A propos de 21 cas d'hypsarhythmia de Gibbs. Son traitment spectaculaire par L'ACTH. Acta Neurol Psychiatr Berg. 1958;58:130-141.

39. Hrachovy RA, Frost JD Jr, Glaze DG. High-dose, long-duration versus low-dose, short-duration corticotropin therapy for infantile spasms. J Pediatr. 1994;124:803-806.

40. Yanagaki S, Oguni H, Hayashi K, et al. A comparative study of highdose and low-dose ACTH therapy for West syndrome. Brain Dev. 1999;21:461-467.

41. Baram TZ, Mitchell WG, Tournay A, et al. High-dose corticotrophin (ACTH) versus prednisone for infantile spasms: a prospective, randomized, blinded study. Pediatrics. 1996;97:375-379.

42. Levy RH, Mattson RH, Meldrum BS, Perucca E. Antiepileptic drugs. 5th ed. Philadelphia: Lippincott Williams and Wilkins; 2002.

43. Elterman RD, Shields WD, Mansfield KA, et al. Randomised trial of vigabatrin in patients with infantile spasms. Neurology. 2001;57:1416-1421.

44. Aicardi J, Hauser E, Steinbock H, et al. Vigabatrin as initial therapy for infantile spasms: a European retrospective survey. Epilepsia. 1996;37:638-642.

45. Covanis A, Theodorou V, Lada C, et al. The first-line use of vigabatrin to achieve complete control of infantile spasms. J Epilepsy. 1998;11: 265-269.

46. Fejerman N, Cersosimo R, Caraballo R, et al. Vigabatrin as a firstchoice drug in the treatment of West syndrome. J Child Neurol. 2000;15:161-165.

47. Granstrom ML, Gaily E, Liukkonen E. Treatment of infantile spasms: results of a population-based study with vigabatrin as the first drug for spasms. Epilepsia. 1999;40:950-957.

48. Vigevano F, Cilio MR. Vigabatrin versus ACTH as first-line treatment for infantile spasms: a randomized, prospective study. Epilepsia 1997;38:1270-1274.

49. Vles JSH, Van der Heyden AMHG, Ghijs A, et al. Vigabatrin in the treatment of infantile spasms. Neuropediatrics. 1993;24:230-231.

50. Cossette P, Riviello JJ, Carmant L. ACTH versus vigabatrin therapy in infantile spasms: a retrospective study. Neurology. 1999;52:1691-1694.

51. Lux AL, Edwards SW, Hancock E, et al. The United Kingdom Infantile Spasms Study (UKISS) comparing hormone treatment with vigabatrin on developmental and epilepsy outcomes to age 14 months: a multicentre randomised trial. Lancet Neurol. 2005;4:712-717.

52. Gross-Tsur V, Banin E, Shahar E, et al. Visual impairment in children with epilepsy treated with vigabatrin. Ann Neurol. 2000;48:60-64.

53. Iannetti P, Spalice A, Perla FM, et al. Visual field constriction in children with epilepsy on vigabatrin treatment. Pediatrics. 2000;106:838-842.

54. Krauss GL, Johnson MA, Miller NR. Vigabatrin-associated retinal cone dysfunction. Electroretinogram and ophthalmologic findings. Neurology. 1997;50:614-618.

55. Siemes H, Spohr HL, Michael T, et al. Therapy of infantile spasms with valproate: results of a prospective study. Epilepsia. 1988;29:553-560.

56. Fisher E, Siemes H, Pund R, et al. Valproate metabolites in serum and urine during antiepileptic therapy in children with infantile spasms: abnormal metabolite pattern associated with reversible hepatotoxicity. Epilepsia. 1992;33:165-171. 
57. Schachter SC. Currently available antiepileptic drugs. Neurotherapeutics. 2007;4:4-11.

58. Nabbout R. A risk-benefit assessment of treatment for infantile spasms. Drug Saf. 2001;24:813-828.

59. Chamberlain MC. Nitrazepam for refractory infantile spasms and the Lennox-Gastaut syndrome. J Child Neurol. 1996;11:31-34.

60. Volzke E, Doose H, Stephan E. The treatment of infantile spasms and hypsarrhythmia with mogadon. Epilepsia. 1967;8:64-70.

61. Dreifuss F, Farwell J, Holmes G, et al. Infantile spasms, comparative trial of nitrazepam and corticotropin. Arch Neurol. 1986;43: $1107-1110$.

62. Murphy JV, Sawasky F, Marquardt KM, Harris DJ. Deaths in young children receiving nitrazepam. J Pediatr. 1987;111:145-147.

63. Rintahaka PJ, Nakagawa JA, Shewmon DA, et al. Incidence of death in patients with intractable epilepsy during nitrazepam treatment. Epilepsia. 1999;40:492-496.

64. Chung SH, Cox RA. Determination of pyridoxal phosphate levels in the brains of audiogenic and normal mice. Neurochem Res. 1983;8:1245-1259.

65. Ito $\mathrm{M}$, Mikawa $\mathrm{H}$, Taniguchi $\mathrm{T}$, et al. Cerebrospinal fluid GABA levels in children with infantile spasms. Neurology. 1984;4:234-238.

66. Watanabe K. Medical treatment of West syndrome in Japan. $J$ Child Neurol. 1995;10:143-147.

67. Ohtsuka Y, Matsuda M, Ogino T, et al. Treatment of the West syndrome with high-dose pyridoxal phosphate. Brain Dev. 1987;9:418-421.

68. Pietz J, Benninger C, Schafer H, et al. Treatment of infantile spasms with high-dosage vitamin B6. Epilepsia. 1993;34:757-763.

69. Striano P, Battaglia S, Giordano L, et al. Two novel ALDH7A1 (antiquitin) splicing mutations associated with pyridoxine-dependent seizures. Epilepsia. 2009;50:933-936.

70. Leppik IE. Zonisamide: chemistry, mechanism of action, and pharmacokinetics. Seizure. 2004;13(Suppl 1):S5-S9.

71. Yanai S, Hanai T, Narazaki O. Treatment of infantile spasms with zonisamide. Brain Dev. 1999;21:157-161.

72. Kawawaki H, Tomiwa K, Shiraishi K, et al. Efficacy of zonisamide in West syndrome [abstract]. No To Hattatsu. 1999;31:263-267.

73. Suzuki Y, Nagai T, Ono J, et al. Zonisamide monotherapy in newly diagnosed infantile spasms. Epilepsia. 1997;38:1035-1038.

74. Suzuki Y, Imai K, Toribe Y, et al. Long-term response to zonisamide in patients with West syndrome. Neurology. 2002;58:1556-1559.

75. Lotze TE, Wilfong A. Zonisamide treatment for symptomatic spasms. Neurology. 2004;62:296-298.

76. Privitera MD. Topiramate: a new antiepileptic drug. Ann Pharmacother. 1997;31:1164-1173.

77. Glauser TA, Clark PO, Strawsburg R. A pilot study of topiramate in the treatment of infantile spasms. Epilepsia. 1998;39:1324-1328.

78. Glauser TA, Clark PO, McGee K. Long-term response to topiramate in patients with West syndrome. Epilepsia. 2000;41(Suppl 1): S91-94.

79. Hosain SA, Merchant S, Solomon GE, Chutorian A. Tropiramate for the treatment of infantile spasms. J Child Neurol. 2006;21:17-19.

80. Korinthenberg R, Schreiner A. Topiramate in children with west syndrome: a retrospective multicenter evaluation of 100 patients. JChild Neurol. 2007;22:302-306.

81. Hurst DL, Rolan TD. The use of felbamate to treat infantile spasms. J Child Neurol. 1995;10:134-144.

82. Coppola G, Pascotto A. Felbamate in refractory infantile spasms. Epilepsia. 1997;38 Suppl:37.

83. Veggiotti P, Cieuta C, Rey E, et al. Lamotrigine in infantile spasms [letter]. Lancet. 1994;44:1375-1376.

84. Cianchetti C, Pruna D, Coppola G, Pascotto A. Low-dose lamotrigine in West syndrome. Epilepsy Res. 2002;51:199-200.

85. Lagae L, Buyse G, Deconink A, Ceulemans B. Effect of levetiracetam in refractory childhood epilepsy syndromes. Eur J Paediatr Neurol. 2003;7(3):123-128.

86. Lawlor KM, Devlin AM. Levetiracetam in the treatment of infantile spasms. Eur J Paediatr Neurol. 2005;9:19-22.
87.Gümüş H, Kumandaş S, Per H. Levetiracetam monotherapy in newly diagnosed cryptogenic West syndrome. Pediatr Neurol. 2007;37:350-353.

88. Matsumoto A, Kumagai T, Takeuchi T, Miyazaki S, Watanabe K. Clinical effects of thyrotropin-releasing hormone for severe epilepsy in childhood: a comparative study with ACTH therapy. Epilepsia. 1987;28:49-55.

89. Takeuchi Y, Matsushita H, Kawano H, Sakai H, Yoshimoto K, Sawada $\mathrm{T}$. Thyrotropin-releasing hormone increases cerebrospinal fluid concentration of kynurenine. Neuroreport. 1999 26;10:3601-3603.

90. Takeuchi Y, Takano T, Abe J, Takikita S, Ohno M. Thyrotropinreleasing hormone: role in the treatment of West syndrome and related epileptic encephalopathies. Brain Dev. 2001;23:662-667.

91. Deng PY, Porter JE, Shin HS, Lei S. Thyrotropin-releasing hormone increases GABA release in rat hippocampus. $J$ Physiol. 2006;577: 497-511.

92. Kubek MJ, Garg BP. Thyrotropin-releasing hormone in the treatment of intractable epilepsy. Pediatr Neurol. 2002;26:9-17.

93. Gee KW, McCauley LD, Lan NC. A putative receptor for neurosteroids on the GABAA receptor complex: the pharmacological properties and therapeutic potential of epalons. Crit Rev Neurobiol. 1995;9 (2 and 3):207-227.

94. Belelli D, Lambert JJ. Neurosteroids: endogenous regulators of the GABAA receptor. Nat Rev Neurosci. 2005;6:565-575.

95. Kerrigan JF, Shields WD, Nelson TY, et al. Ganaxolone for treating intractable infantile spasms: a multicenter, open-label, add-on trial. Epilepsy Res. 2000;42:133-139.

96. Yamamoto H, Asoh M, Murakami H, Kamiyama N, Ohta C. Liposteroid (dexamethasone palmitate) therapy for West syndrome: a comparative study with ACTH therapy. Pediatr Neurol. 1998;18:415-419.

97. Yamamoto H, Fukuda M, Miyamoto Y, Murakami H, Kamiyama N. A new trial liposteroid (dexamethasone palmitate) therapy for intractable epileptic seizures in infancy. Brain Dev. 2007;29:421-424.

98. Debus OM, Kurlemann G; Study group. Sulthiame in the primary therapy of West syndrome: a randomized double-blind placebocontrolled add-on trial on baseline pyridoxine medication. Epilepsia. 2004;45:103-108.

99. Ariizumi M, Baba K, Hibio S, et al. Immunoglobulin therapy in West syndrome. Brain Dev. 1987;9:422-425.

100. Echenne B, Dulac O, Parayre-Chanez MJ, et al. Treatment of infantile spasms with intravenous gammaglobulines. Brain Dev. 1991;13:313-319.

101. Kossoff EH, Pyzik PL, McGrogan JR, Vining EP, Freeman JM. Efficacy of the ketogenic diet for infantile spasms. Pediatrics. 2002;109:780-783.

102. Eun SH, Kang HC, Kim DW, Kim HD. Ketogenic diet for treatment of infantile spasms. Brain Dev. 2006;28:566-571.

103. Kossoff EH, Hedderick EF, Turner Z, Freeman JM. A case-control evaluation of the ketogenic diet versus ACTH for new-onset infantile spasms. Epilepsia. 2008;49:1504-1509.

104. Ballaban-Gil K, Callahan C, O’Dell C, Pappo M, Moshé S, Shinnar S. Complications of the ketogenic diet. Epilepsia. 1998;39:744-748.

105. Kang HC, Chung DE, Kim DW, Kim HD. Early- and late-onset complications of the ketogenic diet for intractable epilepsy. Epilepsia. 2004;45:1116-1123.

106. Freeman JM, Kossoff EH, Hartman AL. The ketogenic diet: one decade later. Pediatrics. 2007;119:535-543.

107. Zafeiriou DI, Kontopoulos EE, Tsikoulas IG. Adrenocorticotropic hormone and vigabatrin treatment of children with infantile spasms underlying cerebral palsy. Brain Dev. 1996;18:450-452.

108. Schlumberger E, Dulac O. A simple effective and well-tolerated treatment regime for West syndrome. Dev Med Child Neurol. 1994;36:863-872.

109. Buoni S, Zannolli R, Strambi M, Fois A. Combined treatment with vigabatrin and topiramate in West syndrome. $J$ Child Neurol. 2004;19:385-386.

110. Kalayci O, Coskun T, Tokatli A, et al. Infantile spasms as the initial symptom of biotinidase deficiency. J Pediatr. 1994;124:103-104. 
111. Zhongshu Z, Weiming Y, Yukio F, Cheng-LNing Z, Zhixing W. Clinical analysis of West syndrome associated with phenylketonuria. Brain Dev. 2001;23:552-557.

112. Chugani HT, ShieldsWD, Shewmon DA, et al. Infantile spasms. I. PET identifies focal cortical dysgenesis in cryptogenic cases for surgical treatment. Ann Neurol. 1990;27:406-413.

113. Chugani TH, Shewmon AD, Shields DW, et al. Surgery for intractable infantile spasms: neuroimaging perspectives. Epilepsia. 1993;34:764-771.

114. Asarnow RF, LoPresti C, Guthrie D, Elliott T, Cynn V, Shields WD, Shewmon DA, Sankar R, Peacock WJ. Developmental outcomes in children receiving resection surgery for medically intractable infantile spasms. Dev Med Child Neurol. 1997;39:430-440.

115. Chuang MF, Harnod T, Wang PJ, et al. Effect of multiple subpial transection on patients with uncontrolled atypical infantile spasms. Epilepsia. 2006;47:659-660.

116. Kang HC, Jung da E, Kim KM, Hwang YS, Park SK, Ko TS. Surgical treatment of two patients with infantile spasms in early infancy. Brain Dev. 2006;28:453-457.
117. Pinard JM, Delalande O, Chiron C, et al. Callosotomy for epilepsy after West syndrome. Epilepsia. 1999;40:1727-1734.

118. National Institute for Clinical Excellence (NICE): Technology Appraisal Guidance 79, Newer Drugs for Epilepsy in Children (www.nice.org/uk/TA 079 guidance) and Clinical Guideline 20, The Epilepsies: The Diagnosis and Management of the Epilepsies in Adults and Children in Primary and Secondary Care, October 2004. (www. nice.org/uk/CG020NICE guideline).

119. Scottish Intercollegiate Guidelines Network. Diagnosis and management of epilepsies in children and young people: a national clinical guideline. Edinburgh, Scottish Intercollegiate Guidelines Network, March 2005. Available at www.sign.ac.uk/pdf/sign81.pdf.

120. Stafstrom CE, Holmes GL. Infantile spasms: criteria for an animal model. Int Rev Neurobiol. 2002;49:391-411.

121. Philippi H, Wohlrab G, Bettendorf U, et al. Electroencephalographic evolution of hypsarrhythmia: toward an early treatment option. Epilepsia. 2008;49:1859-1864.

122. Hancock EC, Osborne JP, Edwards SW. Treatment of infantile spasms. Cochrane Database Syst Rev. 2008; Issue 4. Art. No.: CD001770.
Neuropsychiatric Disease and Treatment

\section{Publish your work in this journal}

Neuropsychiatric Disease and Treatment is an international, peerreviewed journal of clinical therapeutics and pharmacology focusing on concise rapid reporting of clinical or pre-clinical studies on a range of neuropsychiatric and neurological disorders. This journal is indexed on PubMed Central, the 'PsycINFO' database and CAS, and is the official

\section{Dovepress}

journal of The International Neuropsychiatric Association (INA). The manuscript management system is completely online and includes a very quick and fair peer-review system, which is all easy to use. Visit http://www.dovepress.com/testimonials.php to read real quotes from published authors. 